\title{
Análise da variação da temperatura e umidade no período de pré-estação chuvosa na cidade de Sobral/CE
}

\author{
Analysis of temperature and humidity variation in the pre-rainy season in the city of Sobral \\ Análisis de la varación de temperature y humedad en el período previamente a lluvias en la ciudad \\ de Sobral/CE
}

Recebido: 15/12/2021 | Revisado: 20/12/2021 | Aceito: 24/12/2021 | Publicado: 26/12/2021

\author{
Francisco Gerson Lima Muniz \\ ORCID: https://orcid.org/0000-0003-3863-0270 \\ Universidade Estadual do Ceará, Brasil \\ E-mail: gersongeo8@gmail.com \\ Isorlanda Caracristi \\ ORCID: https://orcid.org/0000-0002-3777-7417 \\ Universidade Estadual Vale do Acaraú, Brasil \\ E-mail: icaracristi@hotmail.com
}

\begin{abstract}
Resumo
Este artigo visa analisar a variabilidade da temperatura e umidade relativa do ar durante na estação pré-chuvosa em ambiente semiárido. Para isso, dados relativos a esses elementos climáticos foram coletados através de mini dataloggers abrigados em estruturas de PVC instaladas em cinco pontos amostrais ao longo da cidade de Sobral/CE. A pesquisa foi balizada pelos pressupostos teóricos definidos pelo professor Carlos Augusto de Figueiredo Monteiro, que definiu uma estrutura teórica e metodológica para a compreensão do fator urbano, através do Sistema Clima Urbano (SCU). Os dados correspondem a três dias de coletas horárias ininterruptas. Os resultados mostram uma atuação fora do comum da ZCIT, o que interferiu diretamente nos resultados, através de um aumento na precipitação e na nebulosidade. Verificou-se, ainda, para o período estudado, as temperaturas estiveram sempre elevadas, embora apresentassem variabilidade, assim como a umidade relativa do ar. Ao final, evidenciou-se uma das mais marcantes características do semiárido do nordeste brasileiro: as altas temperaturas.
\end{abstract}

Palavras-chave: Temperatura; Umidade relativa do ar; Variabilidade climática.

\begin{abstract}
This article aims to analyze the variability of temperature and relative humidity during the pre-rainy season in a semiarid environment. For this, data related to these climatic elements were collected through mini dataloggers housed in PVC structures installed in five sample points throughout the city of Sobral/CE. The research was guided by the theoretical assumptions defined by Carlos Augusto de Figueiredo Monteiro, who defined a theoretical and methodological framework for understanding the urban factor, through the Urban Climate System (SCU). The data correspond to three days of uninterrupted hourly collections. Our results show an unusual performance by ZCIT, which directly interfered in the results, through an increase in precipitation and cloud cover. We also found that, for the studied period, temperatures were always high, although they showed variability, as well as the relative humidity of the air. In the end, one of the most striking characteristics of the semiarid region of northeastern Brazil is evident, high temperatures.
\end{abstract}

Keywords: Temperature; Relative humidity; Climate variability.

\section{Resumen}

Este artículo tiene como objetivo analizar la variabilidad de la temperatura y la humedad relativa durante una época pre-lluviosa en un ambiente semiárido. Para eso, se recolectaron datos relacionados con estos elementos climáticos a través de mini dataloggers alojados en estructuras de PVC instaladas en cinco puntos de muestreo a lo largo de la ciudad de Sobral / CE. La investigación estuvo guiada por los supuestos teóricos definidos por el profesor Carlos Augusto de Figueiredo Monteiro, quien definió un marco teórico y metodológico para la comprensión del factor urbano, a través del Sistema Climático Urbano (SCU). Los datos corresponden a tres días de cobros horarios ininterrumpidos. Nuestros resultados muestran un comportamiento inusual del ZCIT, que interfirió directamente en los resultados, a través de un aumento de la precipitación y la nubosidad. También encontramos que, para el período estudiado, las temperaturas siempre fueron altas, aunque presentaban variabilidad, así como la humedad relativa del aire. Al final, una de las características más llamativas de la región semiárida del noreste de Brasil es evidente, las altas temperaturas.

Palabras clave: Temperatura; Humedad relativa del aire; Variabilidad climática. 


\section{Introdução}

Os climas globais recebem grande atenção por parte dos estudiosos e da mídia em relação a outros problemas ambientais, uma vez que a temperatura é o principal elemento que afeta diretamente a sensação/percepção ambiental, principalmente em ambientes urbanos. Para compreender os elementos climáticos de uma localidade, é necessário analisar seu contexto, considerando as características locais e a circulação geral da atmosfera.

A temperatura do ar é um dos atributos mais importantes a ser observado. O aquecimento da superfície se deve ao transporte de calor - principalmente por condução - entre a superfície e a atmosfera terrestre e a variação da temperatura é motivada pelo balanço de energia na superfície. Fatores como irradiância solar, nebulosidade, atuação eólica, umidade atmosférica e relevo exercem influência sobre a temperatura. No contexto urbano, deve-se levar em conta ainda a cobertura do terreno que, como os demais fatores, interferem no microclima (Pereira; Angelocci \& Sentelhas, 2002).

Para a compreensão de um clima local, é essencial considerar as variações diárias de temperatura e umidade relativa do ar. A análise de tais dados permite que se estabeleça uma relação com as variações dos elementos climáticos, dos tipos de tempo transcorrentes e das formas de circulação regional, elementos básicos para determinar o clima e sua relação com outros fatores do ambiente.

A ausência de estações meteorológicas impede uma investigação mais profunda na maioria das cidades brasileiras. Essa é a realidade vivenciada em Sobral/CE, onde os dados oficiais não correspondem à realidade da cidade, uma vez que seu crescimento se deu em sentido oposto à localização da estação meteorológica oficial. Assim, tomando esse município como área de estudo analisou-se dados de temperatura e umidade relativa do ar, a partir de informações coletadas em cinco pontos da cidade, visando compreender a variação desses elementos climáticos durante a estação pré-chuvosa (dezembro e janeiro) no ambiente semiárido.

Neste contexto, o presente trabalho tem como objetivo observar e analisar o comportamento dos elementos do clima (temperatura e umidade) no período de pré-estação chuvosa no contexto de uma cidade no semiárido nordestino brasileiro

\section{2. Área de Estudo}

Sobral/CE está localizada aproximadamente a $230 \mathrm{~km}$ da capital Fortaleza/CE por via rodoviária (BR-222). Inserida no semiárido nordestino sob as coordenadas de $3^{\circ} 41^{\prime} 10^{\prime \prime}$ de latitude (S) e $40^{\circ} 20^{\prime} 59^{\prime \prime}$ de longitude (WGr), a cidade possui altimetria média de $70 \mathrm{~m}$. Com extensão territorial total de $2.123 \mathrm{~km}^{2}$, o município é formado por 17 distritos e equivale a 1,43\% do território estadual (Figura 1). 
Figura 1 - Localização do município de Sobral/CE e de sua sede.

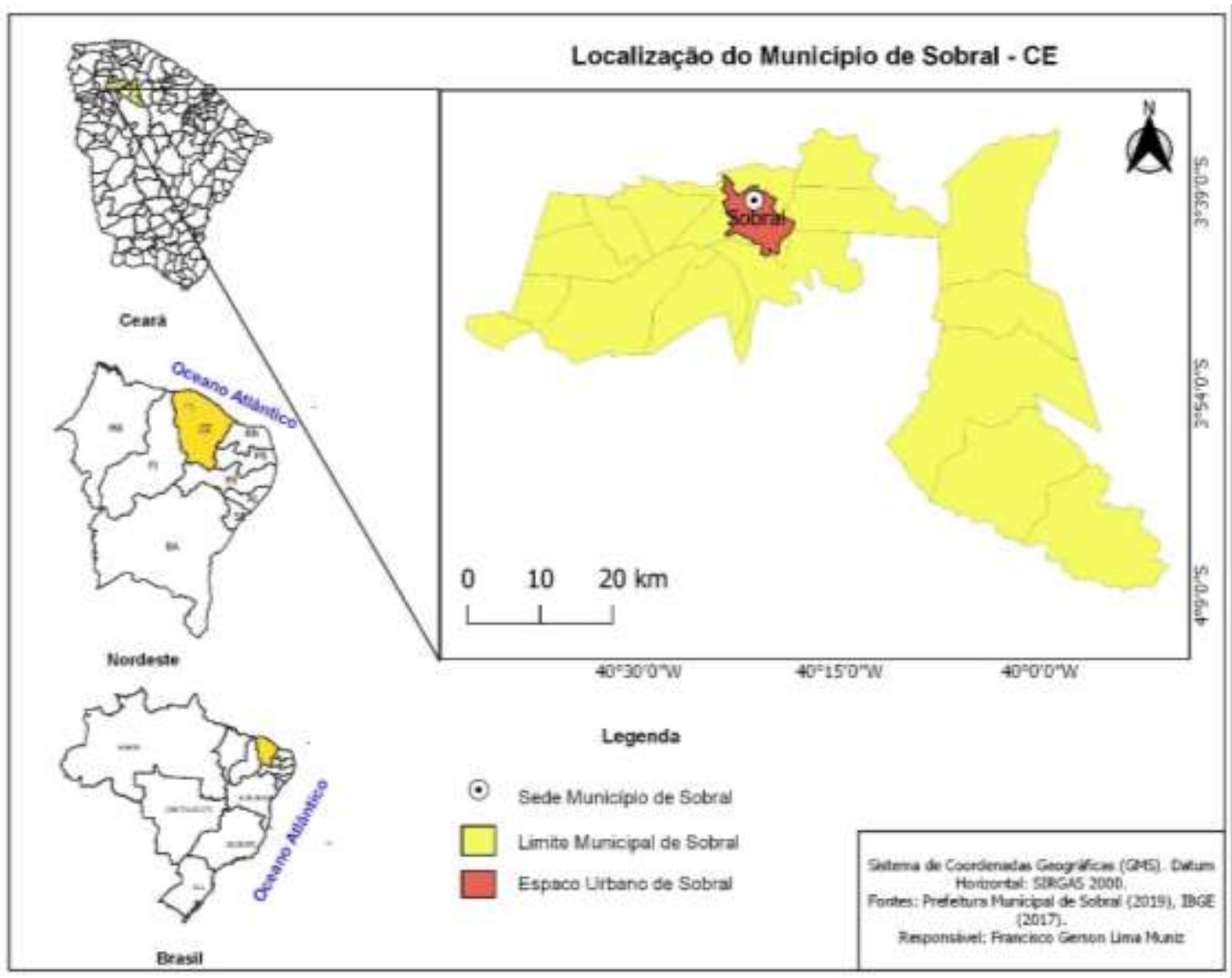

Fonte: Elaborado pelos autores.

A cidade situa-se, em sua maior parte, sobre a Superfície Sertaneja, contudo há outras unidades morfoculturais, como a planície do rio Acaraú e o Maciço Residual Meruoca-Rosário. Esses ambientes naturais exercem papel essencial na constituição do clima local, enquanto o leito do rio Acaraú é canal de ventos e distribuição de umidade para cidade. O Maciço Residual da Meruoca participa ativamente da caracterização ambiental regional do semiárido como dispersor de águas, induzindo a formação de chuvas orográficas, além de abrigar nascentes de vários riachos. O maciço também desempenha a função de indução de brisas, uma vez que, “devido ao aquecimento diferenciado ao longo do dia entre a serra e o vale, é gerado um sistema de brisas semelhante ao mecanismo das brisas litorâneas" (Caracristi, 2000, p. 6).

No contexto geral, os atributos climáticos são de elevadas temperaturas o ano todo, com baixa pluviometria (Figura 2) e grande índice de insolação, o que gera um déficit no balanço hídrico. Conforme a classificação de Köppen e Gaussen, apud Caracristi (2000), os tipos climáticos são BSw’h e 4aTh, respectivamente: clima quente e semiárido de seca acentuada, com déficit hídrico de sete a oito meses, estabelecendo a sazonalidade dos períodos chuvoso e seco.

Já para a Fundação Cearense de Meteorologia e Recursos Hídricos (FUNCEME), a cidade de Sobral apresenta clima Tropical Quente Semiárido, com registro de pluviometria histórica de $821,6 \mathrm{~mm} /$ ano e temperatura média entre $26^{\circ}$ e $28^{\circ} \mathrm{C}$. 
Figura 2 - Precipitação média mensal em Sobral/CE (Normal Climatológica 1961-1990 / 1981-2010).

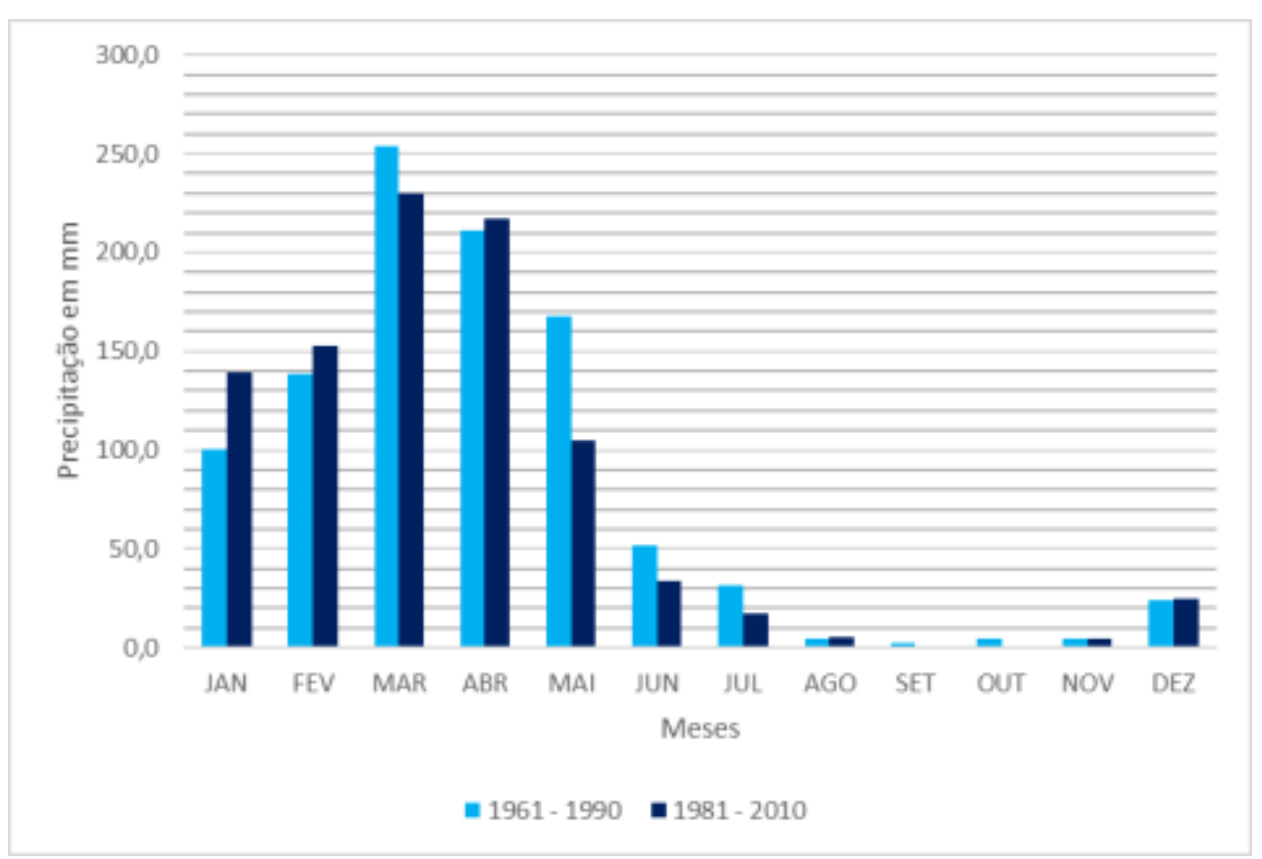

Fonte: Elaborado pelos autores a partir de dados do INMET.

Segundo dados do Instituto Nacional de Meteorologia (INMET), a média da temperatura máxima está sempre acima de $36^{\circ} \mathrm{C}$ nos meses de setembro a dezembro. Esses valores, acompanhados da baixa umidade para o período, resultam em grande desconforto térmico (Muniz, 2016; Muniz \& Caracristi, 2019). Já a temperatura máxima absoluta foi superior a $36^{\circ} \mathrm{C}$ em todos os meses, chegando a ficar acima dos $39^{\circ} \mathrm{C}$ entre setembro e novembro. Já nos meses de pré-estação chuvosa (dezembro e janeiro) há uma redução, sobretudo em janeiro, quando a média da temperatura máxima fica em $34^{\circ} \mathrm{C}$ e a temperatura média diária em pouco abaixo de $28^{\circ} \mathrm{C}$.

As Normais Climatológicas (NC) do INMET (1961-1990/1981-2010) expõem as médias da temperatura do ar (Figura 3) da cidade. Abril e maio são os meses com temperaturas mais brandas. À medida que os meses avançam ao longo do ano, as temperaturas se elevam, atingindo uma média superior a $28^{\circ} \mathrm{C}$ entre setembro e dezembro, período popularmente conhecido pelas altas temperaturas. Na NC de 1981-2010, há uma ligeira elevação das temperaturas nesses meses em comparação à NC 1961-1990.

Figura 3 - Média da temperatura do ar em Sobral/CE (NC 1961-1990/1981-2010).

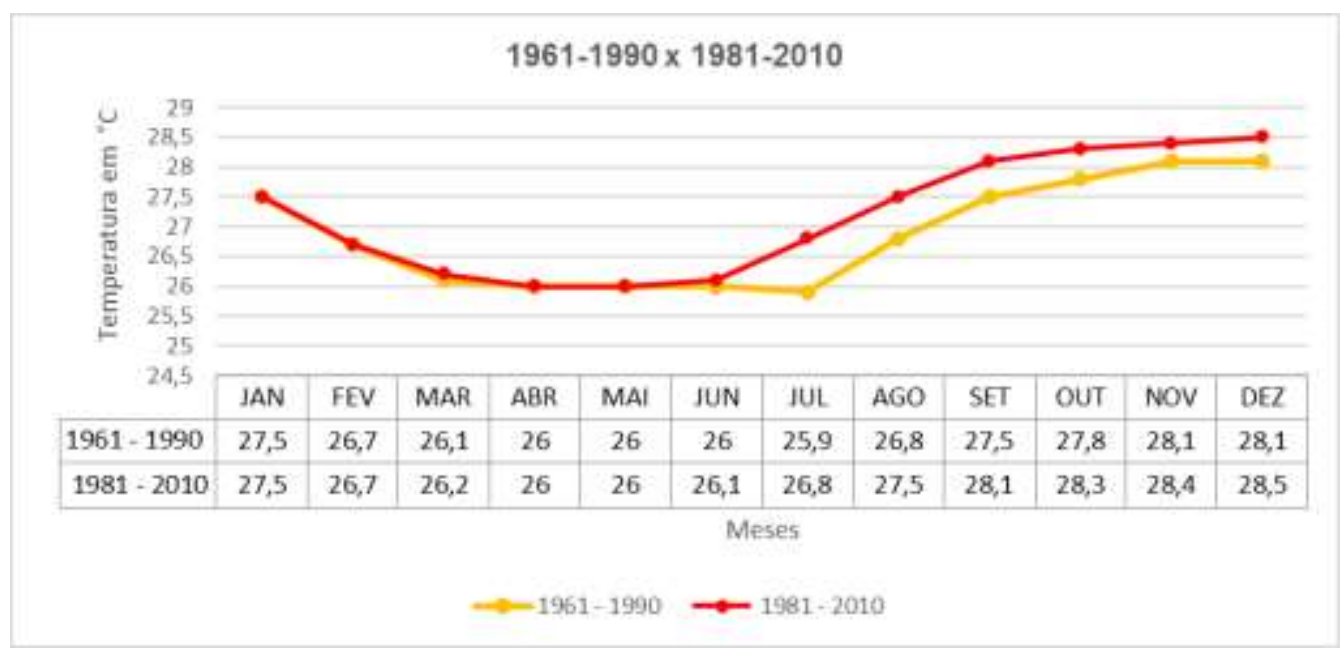

Fonte: Elaborado pelos autores a partir de dados do INMET. 
As Figuras 4A e 4B, a seguir, mostram índices de insolação sempre elevados, constantemente acima das 150 horas mensais, sendo outubro (NC 1981-2010) o mês com maior acúmulo mensal. Nos meses finais do ano, a radiação se intensifica, pois há poucas nuvens para diminuir a penetração dos raios solares na superfície terrestre.

Figura 4 - (A) NC da insolação. (B) Relação entre insolação e nebulosidade (1981/2010).

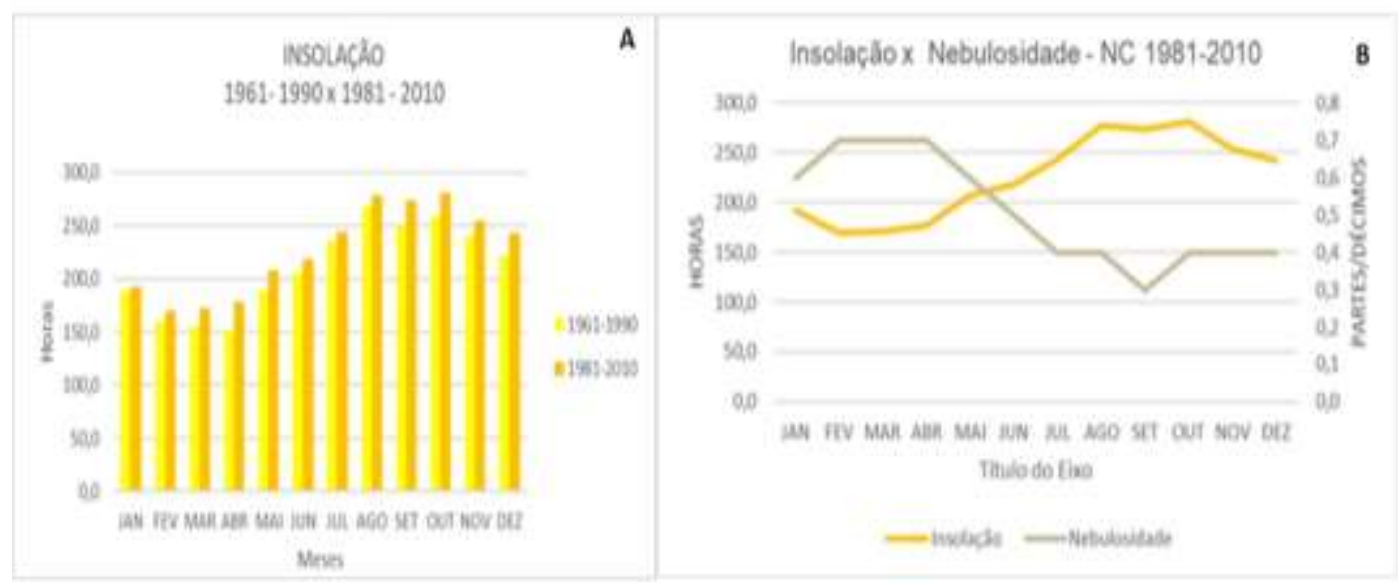

Fonte: Elaborado pelos autores a partir de dados do INMET.

Devido à sua localização latitudinal, Sobral está inserida na faixa climática tropical, região que mais sofre com a incidência dos raios solares, caracterizando-se pelo clima semiárido. Esse clima é típico do interior do Nordeste, abrangendo a região conhecida como o "Polígono das Secas", que corresponde a quase todo o sertão nordestino (Conti, 2005).

Conforme Ab’Saber (1974), o semiárido do Nordeste Brasileiro (NEB) torna a região uma das mais quentes do globo, envolvendo uma forte entrada de radiação solar, além de precipitações irregulares ou mesmo escassas, na área principal do domínio seco. Ainda segundo o autor, a atuação regional das massas de ar no NEB está diretamente associada a "Em" (Equatorial Marítimo), "Ta" (Tropical Atlântico) e possíveis interferências da FPA (Frente Polar Atlântica). O autor também destaca atuação da massa Equatorial Continental (Ec):

[...] por ocasião da ampliação da área de atuação da Ec, por ocasião do deslocamento da convergência intertropical, para leste e para sul, ocorrem chuvas de verão, escassas e irregulares, relacionadas a interferências de submassas úmidas com ar quente predominantemente nos sertões (Ab'Saber, 1974, p.10).

O sistema atmosférico mais atuante no Nordeste brasileiro (NEB) e em Sobral é a Zona de Convergência Intertropical (ZCIT), que gera precipitação na região equatorial. A ZCIT pode ser definida como:

Uma banda de nuvens que circunda a faixa equatorial do globo terrestre, formada principalmente pela confluência dos ventos alísios do hemisfério norte com os ventos alísios do hemisfério sul. De maneira simplista, pode-se dizer, que a convergência dos ventos faz com que o ar, quente e úmido ascenda, carregando umidade do oceano para os altos níveis da atmosfera ocorrendo a formação das nuvens (Funceme, 2002).

Outros sistemas também atuam no NEB. Suas principais características estão sintetizadas no Quadro 1. 
Quadro 1 - Síntese dos sistemas atmosférico atuantes no NEB.

\begin{tabular}{|c|c|}
\hline Sistemas Atmosféricos & Origem e atuações \\
\hline $\begin{array}{l}\text { Imagem do Satélite Meteosat-7, mostrando } \\
\text { a nebulosidade deslocando-se desde a costa } \\
\text { da África até o litoral leste do Brasil. Fonte: } \\
\text { Funceme (2002). }\end{array}$ & $\begin{array}{l}\text { Ondas de Leste } \\
\text { Sua origem está associada aos alísios originados no ASAS. Deslocam- } \\
\text { se de leste para oeste e ocasionam o desaparecimento da inversão } \\
\text { térmica na Massa Tropical Atlântica (MTA), provocando o avanço da } \\
\text { Massa Polar Atlântica (MPA) até as latitudes tropicais, gerando } \\
\text { precipitações de diversas magnitudes (FERREIRA \& MELO, 2005). }\end{array}$ \\
\hline $\begin{array}{l}\text { Imagem do satélite METEOSAT-7, } \\
\text { mostrando o posicionamento de uma Frente } \\
\text { Fria próxima ao sul do estado da Bahia. } \\
\text { Fonte: Funceme (2002) }\end{array}$ & $\begin{array}{l}\text { Frentes Frias (FF) } \\
\text { As FFs são bandas de nuvens organizadas que se formam na região de } \\
\text { confluência entre uma massa de ar frio (mais densa) com uma massa de } \\
\text { ar quente (menos densa). A massa de ar frio penetra por baixo da } \\
\text { massa quente e faz com que o ar quente e úmido suba, forme nuvens e, } \\
\text { consequentemente, as chuvas. A penetração das FFs em latitudes } \\
\text { tropicais entre novembro e janeiro propicia chuvas ao NEB. Sua } \\
\text { atuação ocorre nas porções meridionais da região. }\end{array}$ \\
\hline $\begin{array}{l}\text { Imagem do satélite METEOSAT-7, } \\
\text { mostrando uma Linha de Instabilidade } \\
\text { desde o litoral do estado do Maranhão até o } \\
\text { estado do Rio Grande do Norte. Fonte: } \\
\text { Funceme (2002). }\end{array}$ & $\begin{array}{l}\text { Linhas de Instabilidade (LI) } \\
\text { São bandas de nuvens causadoras de chuva, normalmente do tipo } \\
\text { cumulus, organizadas em forma de linha. São formadas pela grande } \\
\text { quantidade de radiação solar da região tropical, que atinge valores } \\
\text { maiores à tarde, quando a convecção é máxima, com consequentes } \\
\text { chuvas. A proximidade com ZCIT contribui para o incremento das Lis. } \\
\text { Na região, as Lis são oriundas da Massa Equatorial Continental } \\
\text { (MEC). São mais facilmente identificadas nos meses de verão no } \\
\text { hemisfério Sul (dezembro a março), visualizadas ao sul da Linha do } \\
\text { Equador, influenciando as chuvas no litoral norte do Nordeste e regiões } \\
\text { adjacentes e ocorrem no período da tarde e início da noite (Funceme, } \\
\text { 2002). }\end{array}$ \\
\hline
\end{tabular}




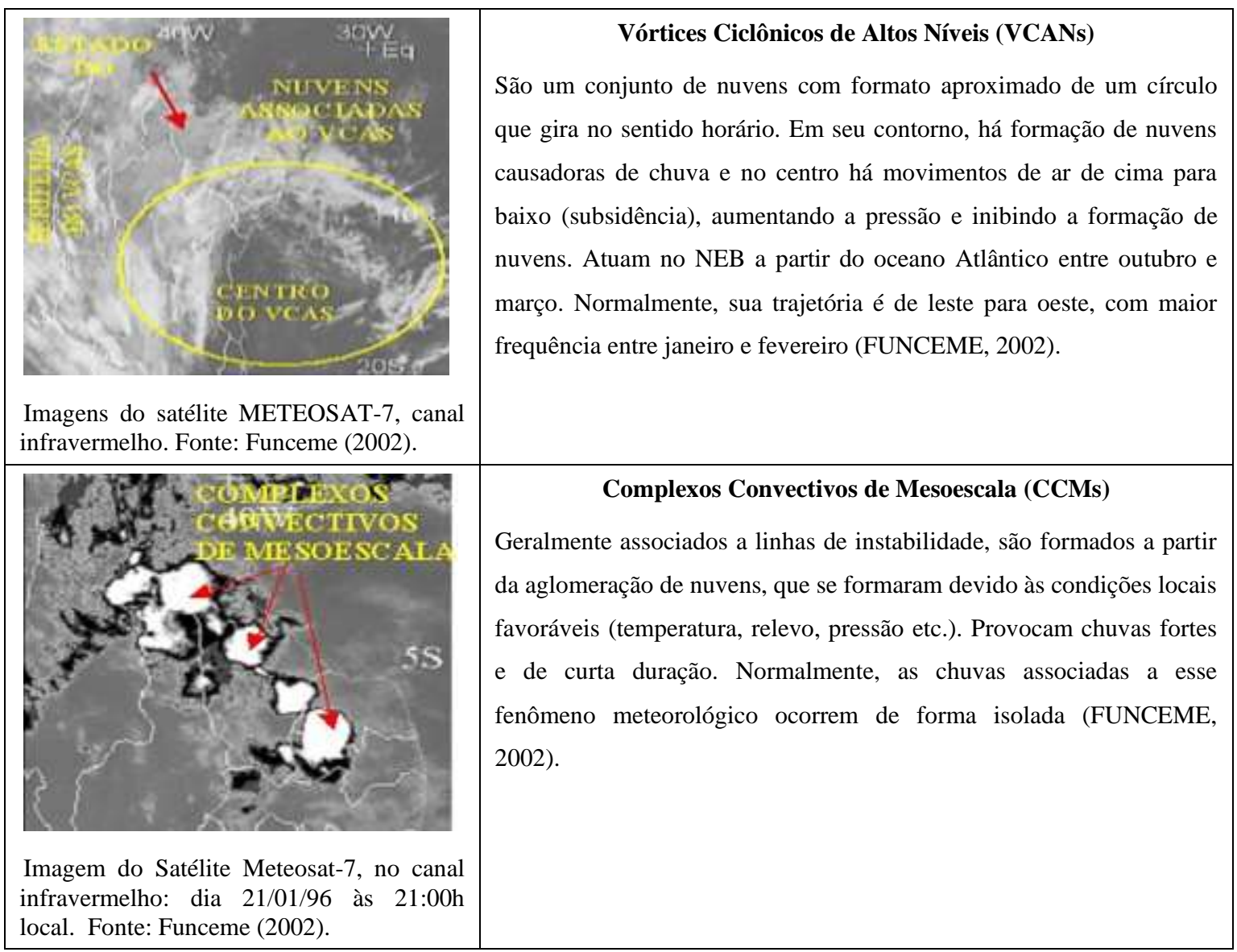

Fonte: Elaborado pelos autores, baseado em FUNCEME (2002).

\section{Metodologia}

Esta pesquisa baseou-se nos pressupostos teóricos de Monteiro (1976; 2003) que, através de uma abordagem sistêmica, definiu uma estrutura teórica e metodológica para a compreensão do fator urbano, através do Sistema Clima Urbano (SCU).

Para Monteiro (2003, p. 20), “o universo urbano está amplamente aberto ao que há de mais interdisciplinar. Em verdade, obedecendo ao caráter antropocêntrico da Geografia, a cidade é, cada vez mais, a morada do Homem." Os elementos climáticos e os atributos físicos que interferem na atmosfera e no ecossistema urbano adquirem características próprias provocadas pela urbanização, especialmente em escala local.

Para análise da temperatura e umidade relativa do ar no período considerado de pré-estação chuvosa do semiárido (verão austral), priorizou-se o subsistema Termodinâmico. A coleta de dados ocorreu em janeiro de 2020, durante dez dias e em cinco pontos distintos de Sobral, com coleta horária em um perfil de 24 horas. Porém, para esta analise, utilizou-se, apenas três dias representativo (15, 16 e 17 de janeiro de 2020), que serviram de base para o estudo. Os pontos amostrais - todos situados no espaço urbano - foram selecionados com base na classificação em Zonas Climáticas Urbanas (Urban Climate Zones - UCZ) (Oke, 2006), uma vez que é necessário expor áreas com características climáticas representativas para se identificar o potencial de cada uma delas sobre o clima local.

A Figura 5 expõe os Postos de Coleta de Dados (PCD) com suas altitudes e coordenadas geográficas. O PCD 1 está inserido na porção noroeste da cidade, que teve boom imobiliário nos anos 2000, resultando em intensa modificação do meio local, inclusive direcionando a urbanização ao Maciço Residual da Meruoca.

O PCD 2 foi instalado em um terreno particular. Localiza-se em uma área que abriga uma das principais vias de 
acesso à cidade no sentido oeste, com inúmeros bairros consolidados há décadas, com população de baixa renda em sua maioria.

Figura 5 - Localização dos PCDs da pesquisa na cidade de Sobral/CE.

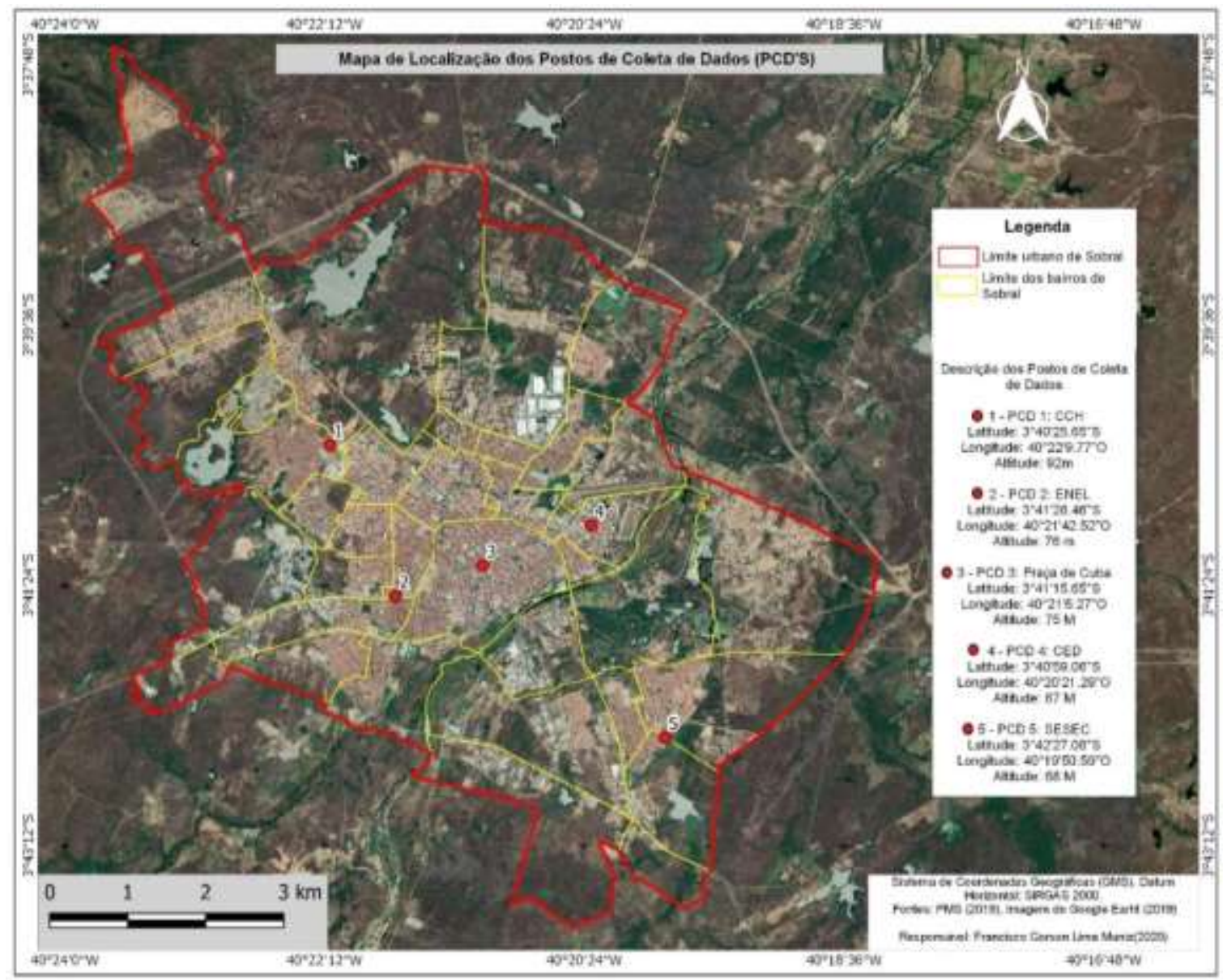

Fonte: Elaborado pelos autores.

O PCD 3, localizado na praça de Cuba, centro da cidade. Histórica e importante praça da cidade, seu espaço teve diversas denominações e usos, inserido no coração econômico da cidade, onde as dinâmicas sociais, políticas e econômicas acontecem de forma intensa. O Centro, apesar de ser espaço de tradicionais famílias sobralenses e de alta renda, encontrou-se comunidades que apresentam diversas famílias de baixa renda social

O PCD 4 foi alojado em espaço público adjacente ao Centro de Educação à Distância (CED), este inserido no contexto de bairros consolidados em décadas anteriores. Área com casas de alto padrão, mas que na última década viu a verticalização se tornar característico.

Por fim, o PCD 5 foi instalado no espaço público vizinho a da Secretaria de Segurança Pública e Cidadania - SESEC. O local situa-se no bairro Cohab I, localizado posterior a margem direita do rio Acaraú, é caracterizado principalmente por casas de baixo padrão.

Os dados foram coletados através de mini dataloggers Highmed $®$ de temperatura e umidade (94 x 44 x $13 \mathrm{~mm}$ ), abrigos de PVC (policloreto de vinil), adaptados de Castelhano \& Roseghini (2011) (Figura 6). Os equipamentos foram instalados em cada ponto amostral para que fossem realizadas medições de 24 horas diárias. 
Figura 6 - (A) Mini datalogger. (B) e (C) Abrigo meteorológico de PVC.

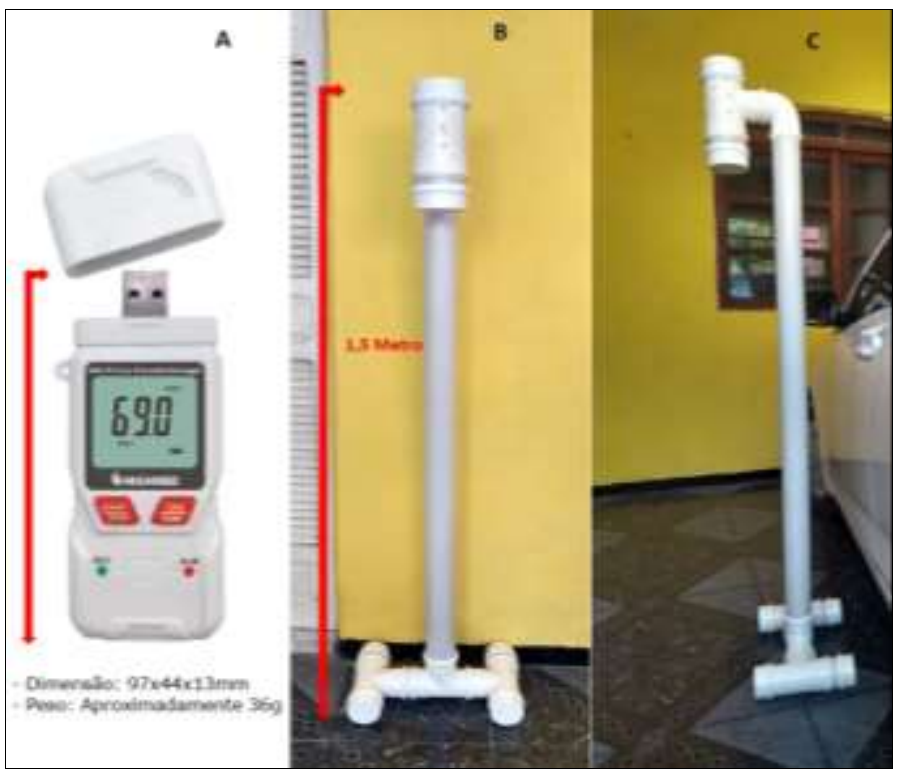

Fonte: Arquivo pessoal.

\section{Resultados e Discussão}

A análise rítmica possibilita gerar um padrão da variação dos atributos do clima, sendo necessário ponderar as características topográficas e de uso e ocupação da área. Para Monteiro,

[...] ritmo climático só poderá ser compreendido através da representação concomitante dos elementos fundamentais do clima em unidades de tempo cronológico pelo menos diárias, compatíveis com a representação da circulação atmosférica regional, geradora dos estados atmosféricos que se sucedem e constituem o fundamento do ritmo. (Monteiro, 1971, p. 9)

Antes de iniciar as análises sinóticas locais, é importante ressaltar o comportamento atmosférico global para o interstício que, segundo o Instituto Nacional de Meteorológia (INMET), estava normal em relação às condições atmosféricas locais, uma vez que a temperatura da superfície do oceano Pacífico apresentava condições naturais, de modo que os dados não foram afetados pela presença de fenômenos como El Niño ou La Niña.

Dentre os dias amostrados, selecionamos três (15 a 17 de janeiro/2020) que expressaram satisfatoriamente a variabilidade climática da região e observou-se as imagens de satélite da área fornecidas pelo Centro de Previsão do Tempo e Estudos Climáticos/ Instituto Nacional de Pesquisas Espaciais (CPTEC/INPE). As imagens são do satélite Goes 16/Canal 13 (Figura 7). 
Figura 7 - Evolução da dinâmica atmosférica dos dias 15 e 16 de janeiro de 2020.

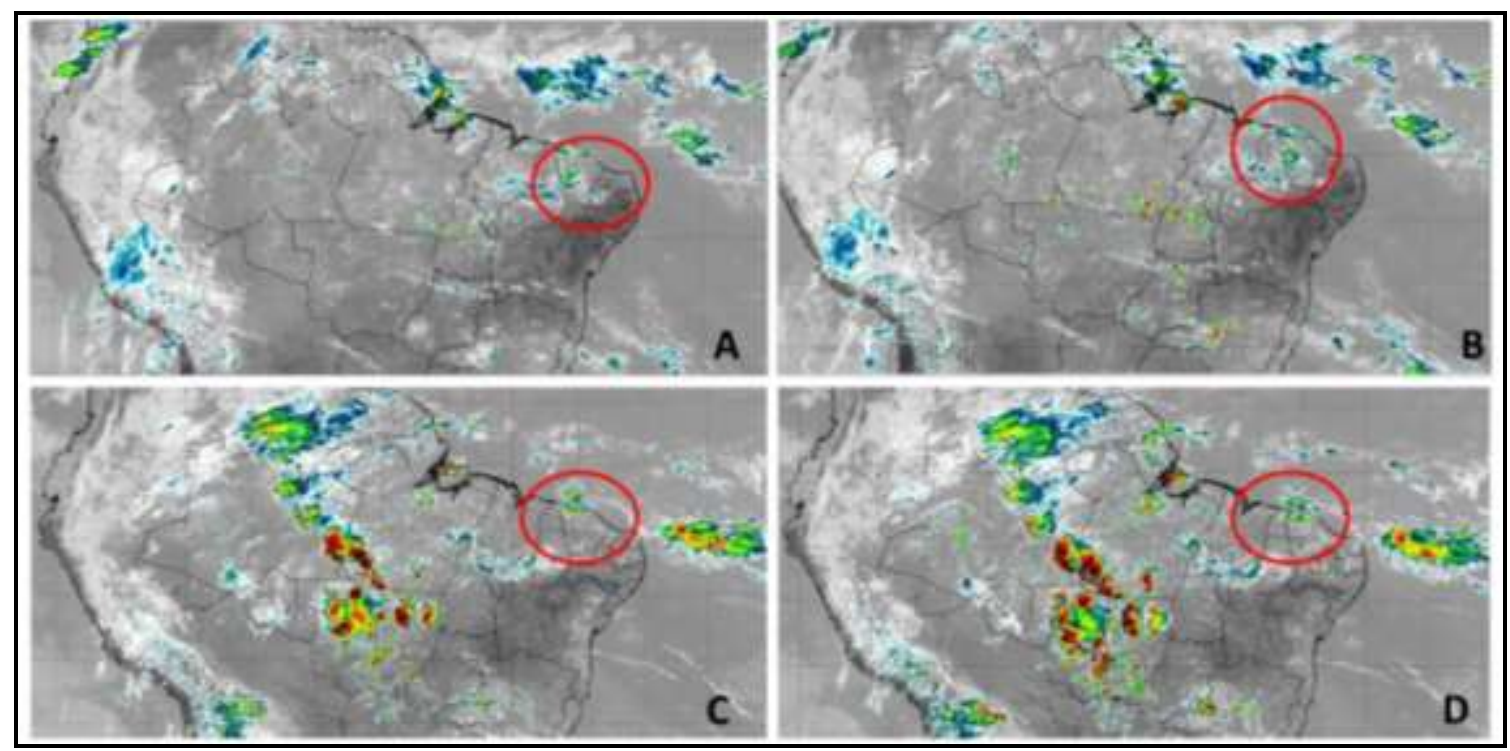

Fonte: Adaptado do satélite GOES 16/Canal 13, CPTEC/INPE.

A Figura 7A corresponde à captura referente ao dia 15 de janeiro às 13 h00 (hora local). Observa-se uma pequena concentração de nuvens, que resultou em uma precipitação de 5,4 mm às 14h. Na Figura 7B, registrada justamente às 14h00, percebe-se a evolução das nuvens e, apesar da pluviosidade ter sido baixa, ela contribuiu significativamente para a variação da temperatura e umidade relativa do ar na área de estudo.

As Figuras 7C e 7D reportam o comportamento atmosféricos para o dia 16, às $13 \mathrm{~h} 00$ e $14 \mathrm{~h} 00$, respectivamente. Apesar de haver poucas nuvens, observou-se em campo uma nebulosidade acentuada durante todo dia, impedindo que a radiação atingisse a superfície terrestre de forma mais intensa. Também presenciou-se uma garoa leve no período vespertino, embora o INMET não tenha registrado pluviosidade para o dia.

A Figura 8 mostra a evolução das condições atmosféricas para do dia 17 de janeiro de 2021. As imagens A, B, C e D, correspondem, respectivamente, aos horários: 13h00, 13h30, 14h00 e 18h00. As três primeiras imagens são significativas para compreender a acentuada variação de temperatura e umidade no dado intervalo, enquanto a imagem D é essencial para o entendimento do sistema atmosférico atuante. 
Figura 8 - Evolução da dinâmica atmosférica em 17 de janeiro de 2020.

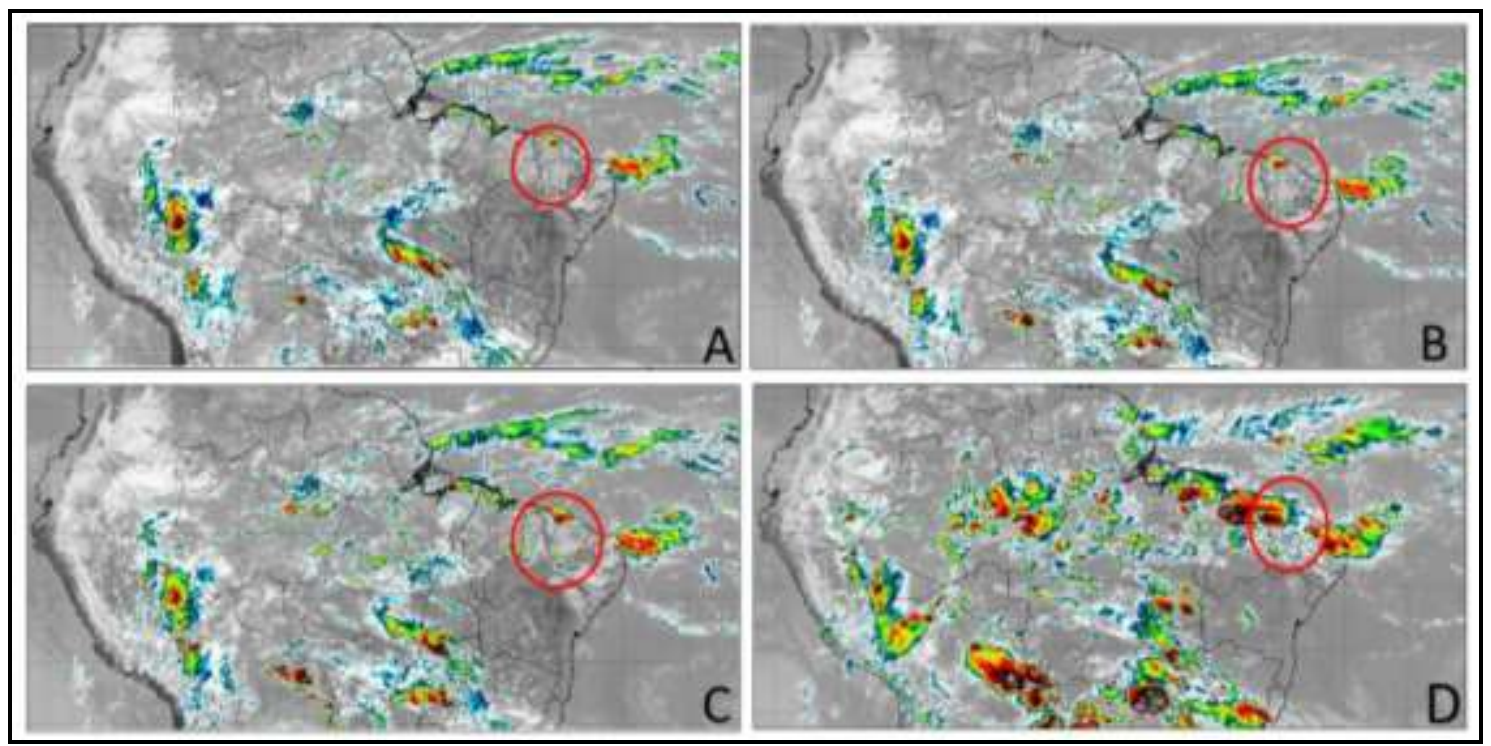

Fonte: Adaptado do satélite GOES 16/Canal 13, CPTEC/INPE.

As imagens do Goes 16 mostram uma banda dupla da ZCIT que se desprendeu devido a um cavado em níveis inferiores, formando uma espécie de pulsos da ZCIT. Geralmente, esse fenômeno ocorre em janeiro e tem curta duração, porém, quando associados aos VCANs, em situações excepcionais, perduram por mais dias e representam fortes acumulados na pluviometria.

Ao longo do dia, o céu esteve bastante nublado, com breves momentos de sol entre nuvens no período da manhã. Após às 13h00, houve uma chuva, registrada em todos as regiões da cidade. A Figura 9 indica um volume de 16,6 mm segundo o INMET para as $14 \mathrm{~h} 00$ e de $1,4 \mathrm{~m} / \mathrm{m}$ para as $15 \mathrm{~h} 00$. Apesar de relativamente pequena, a chuva causou estragos em residências e prédios nas porções norte e noroeste da cidade.

Figura 9 - Pluviosidade em Sobral/CE em 15, 16 e 17 de janeiro de 2020.

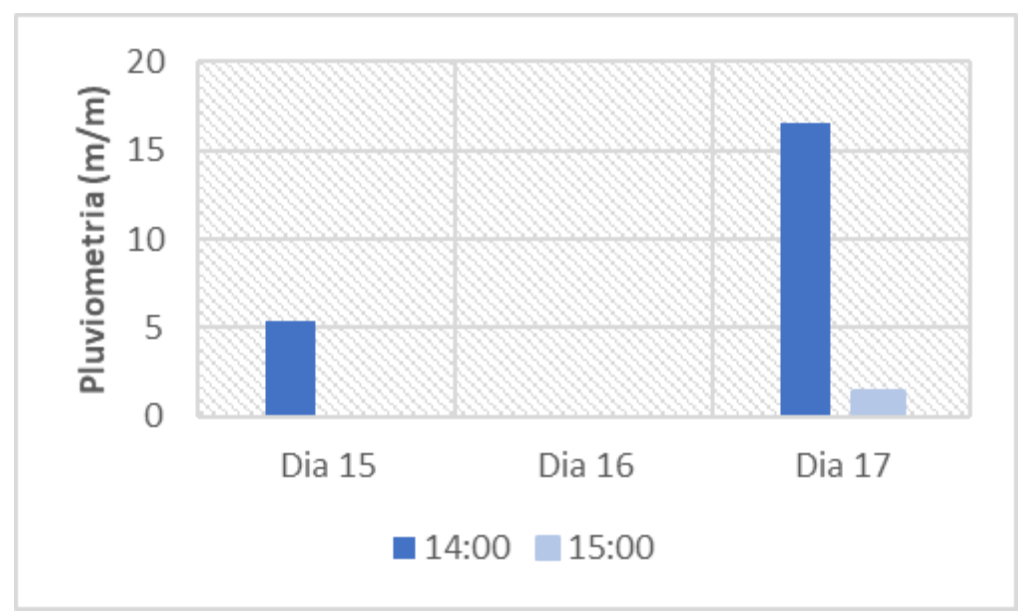

Fonte: Elaborado pelos autores com base em dados do INMET.

Historicamente, a média da temperatura do ar para janeiro é de $27,5^{\circ} \mathrm{C}$. As temperaturas registradas nos três dias selecionados encontram-se próximas a esse valor. No entanto, as temperaturas registradas nos PCDs foram ligeiramente superiores, sobretudo, no dia 16 quando a média foi superior a $28,3^{\circ} \mathrm{C}$ em todos os pontos amostrais, atingindo $29,2^{\circ} \mathrm{C}$ no 
PCD 2 (Figura 10).

Figura 10 - Variação da temperatura do ar em Sobral/CE nos PCDs.

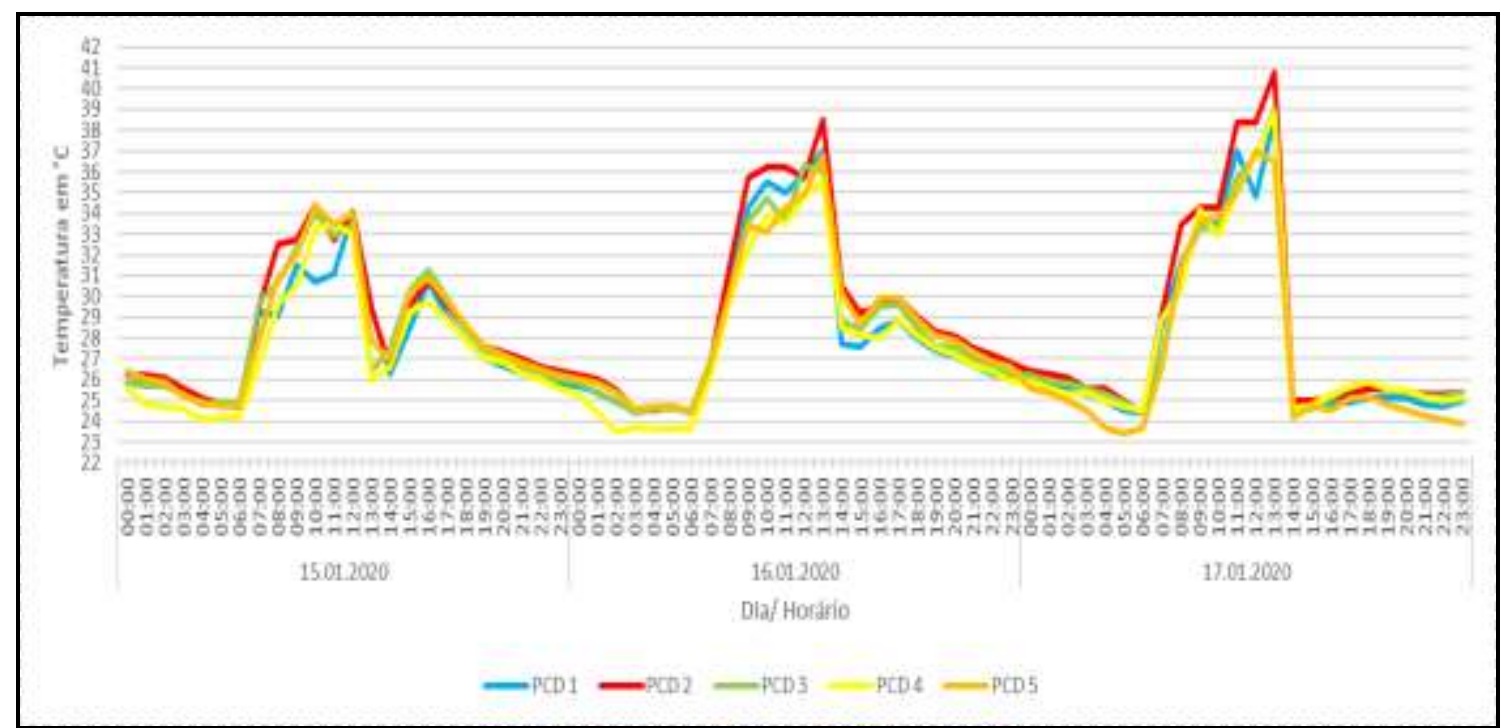

Fonte: Elaborado pelos autores.

No espaço urbano, a temperatura e a umidade relativa do ar seguem uma tendência ao longo do dia. Nas primeiras horas da madrugada, a temperatura segue caindo até apresentar os valores mais baixos entre 5 h00 e $6 \mathrm{~h} 00$. Nas horas subsequentes, a temperatura aumenta gradativamente, atingindo o ápice entre $12 \mathrm{~h} 00$ e 13h00. Após esse horário, há novamente uma tendência de queda, de forma bem lenta.

As amplitudes térmicas referentes aos dias 15,16 e 17 de janeiro foram, respectivamente, $9,9^{\circ} \mathrm{C}, 14,1^{\circ} \mathrm{C}$ e $17,1^{\circ} \mathrm{C}$. O PCD 2 registrou os maiores valores em grande parte dos dias de coleta, apresentando também a maior temperatura $\left(40,8^{\circ} \mathrm{C}\right)$ no universo dos dados coletados, ressaltando que o PCD 2 estava instalado às margens de uma via de acesso à cidade, com grande fluxo de veículos durante todo dia, principalmente no período diurno.

Em contrapartida, o PCD 4 registrou temperaturas mais amenas que os demais, mas ainda elevadas, chegando a $38,8^{\circ} \mathrm{C}$ às $13 \mathrm{~h} 00$ do dia 17 . Essa redução de temperatura em relação aos demais pontos amostrais, pode ser explicada pelo fato de que o mini datalogger do PCD 4 foi instalado em uma região próxima ao leito do rio Acaraú, que influencia fortemente o clima local.

A umidade relativa do ar também oscila em etapas ao longo dia. Na região, o mês de janeiro é caracterizado por forte nebulosidade e possibilidade de precipitações, fato que interfere nos valores da umidade, os quais apresentaram-se acima de $70 \%$ em grande parte dos dados coletados. Algumas exceções - como vertiginosas quedas nos valores de umidade relativa do ar - foram registradas à medida que houve forte elevações de temperatura (Figura 11). 
Figura 11 - Variação da umidade relativa do ar em Sobral/CE nos PCDs.

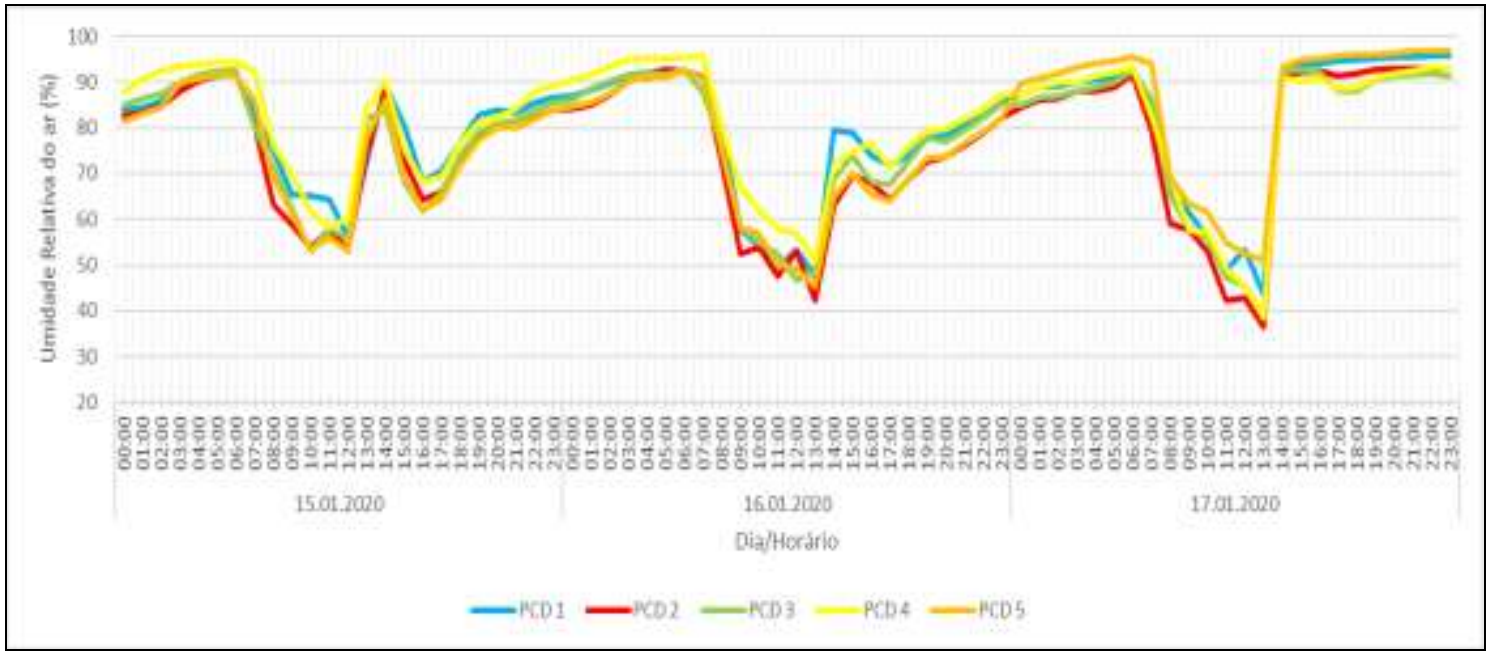

Fonte: Elaborado pelos autores.

O PCD 2 apresentou o menor valor de umidade relativa do ar, registrando 36,4\% às $13 \mathrm{~h}$ do dia 17. Contrariamente, o PCD 4 apresentou os maiores valores em quase todas as coletas, obtendo média superior a 79\%. Esses resultados possivelmente refletem a influência direta do rio Acaraú, situado próximo ao PCD 4.

Os dados coletados correspondem à realidade semiárida, pois mesmo com nebulosidade e pluviosidade significativas em dois dos três dias selecionados, as altas temperaturas prevaleceram. Uma característica de destaque para esse período é a abrupta mudança da temperatura.

Segundo a Figura 10, nos três dias, há picos de temperatura. No entanto, uma hora após a última coleta, observou-se uma abrupta queda dos valores, o que provoca grandes amplitudes térmicas. No dia 15 , a amplitude térmica variou de $4,5^{\circ} \mathrm{C}$ no PCD 1 a $7^{\circ} \mathrm{C}$ nos PCDs 3 e 4, enquanto no dia 16, a variação foi de $6,6^{\circ} \mathrm{C}$ no $\mathrm{PCD} 5$ a 9,3 ${ }^{\circ} \mathrm{C}$ no $\mathrm{PCD} 1$. A umidade relativa do ar seguiu mesma tendência, porém com valores proporcionalmente inversos aos da temperatura, chegando a uma diferença de $26 \%$ no PCD 3 em 15 de janeiro e de 31,5\% no PCD 1 no dia 16.

O dia 17 traz valores expressivos dos elementos observados, possivelmente pela atuação dos pulsos da ZCIT. No interstício das $13 \mathrm{~h} 00$ às $14 \mathrm{~h} 00$, a amplitude térmica e a higrometria atingiram valores elevados em um intervalo muito curto de tempo no período vespertino. Para o mesmo período, foi registrada pluviosidade, gerando elevação da umidade relativa do ar e completa nebulosidade do céu.

Ainda no dia 17, a temperatura do ar atingiu o ápice às 13h00, quando os PCDs 1, 2, 3, 4 e 5 registraram, respectivamente, $38,6^{\circ} \mathrm{C}, 40,8^{\circ} \mathrm{C}, 39^{\circ} \mathrm{C}, 38,8^{\circ} \mathrm{C}$ e $36,5^{\circ} \mathrm{C}$. Na coleta seguinte, a amplitude térmica variou de $12,3^{\circ} \mathrm{C}$ a $15,8^{\circ} \mathrm{C}$. Essa maior diferença foi registrada no PCD 2, enquanto a diferença menos significativa ocorreu no PCD 5 . Para os demais pontos amostrais, a variação foi superior a $14^{\circ} \mathrm{C}$.

A rápida mudança do tempo possivelmente refletiu no conforto térmico da população local. Outro ponto importante nessas mudanças drásticas reflete na saúde de algumas pessoas que sofrem com mudança de tempo, principalmente quando ocorre de forma drástica. No entanto, este são fatos e elementos que devem ser abordados em estudos futuros.

\section{Considerações Finais}

Tomando por base o período analisado, foi possível tecer algumas considerações em relação à variação da temperatura e umidade relativa do ar nos pontos selecionados na cidade e Sobral:

a) As elevadas temperaturas são uma constante no contexto urbano da cidade. Esse fator é acentuado pelas variáveis 
climáticas locais, associadas à conjuntura de espaço urbano (morfologia, sítio e função urbana);

b) Alguns PCDs registraram valores bem superiores aos demais, implicando na necessidade de maior observação e estudo das características locais para uma compreensão mais apurada dos elementos na formação do microclima local;

c) Janeiro, último mês que antecede o período chuvoso, apresenta temperaturas elevadas, no entanto, a variabilidade da temperatura e umidade são uma constante;

d) O principal sistema atmosférico atuante, a ZCIT, teve participação decisiva nos resultados, influenciando diretamente a umidade relativa do ar. A elevada densidade de nuvens para o dia minimizou a intensidade dos raios solares na superfície, intensificando a variabilidade para o período.

\section{Referências}

Ab’Saber. (1974). O domínio morfoclimático semi-árido das caatingas brasileiras. Geomorfologia, 43, 1-39.

Ayoade, J.O. (2003). Introdução à Climatologia para os Trópicos. (14a Ed). Rio de Janeiro: Berthand.

Barros, J.R. \& Zavatini, J. A. (2009). Bases conceituais em climatologia Geográfica. Mercator, 8(16) 22-35.

Caracristi, I. (2000). Estudo integrado do clima da região do médio curso do rio Acaraú: uma análise geográfica do clima local. Revista Essentia, 1.

Caracristi, I. (1996). A Climatologia: Domínios e Métodos. Casa da Geografia de Sobral/UVA, 1(1).

Castelhano, F.N \& Roseghini, W.F.F. (2011). A utilização de policloreto de vinila (PVC) na construção de mini-abrigos meteorológicos para aplicação em campo. Revista Brasileira de Climatologia, 9. 48-55.

Conti, J.B. (2005). A questão climática do Nordeste Brasileiro e os processos de desertificação. Revista Brasileira de Climatologia. 1(1). 7-14. http://www.geografia.fflch.usp.br/abclima.

Ferreira, A.G \& Mello, N.G.S. (2005). Principais sistemas atmosféricos atuantes sobre a região Nordeste do Brasil e a influência dos oceanos Pacífico e Atlântico no clima da região. Revista Brasileira de Climatologia, 1 (1). 15-28.

Funceme (2002). Sistemas meteorológicos causadores de chuvas na região nordeste do Brasil. Boletim especial. http://www.funceme.com.br

Monteiro, C.A.F. (1971). Análise rítmica em climatologia. Problemas da atualidade climática em São Paulo e achegas para um programa de trabalho. São Paulo, Climatologia, 1. 1-21.

Monteiro, C. A. F. (1976). Teoria e clima urbano. (tese de doutorado) Instituto de Geografia, Universidade de São Paulo, SP, São Pauo, Brasil.

Monteiro, C.A.F \& Mendonça, F. (2003). Clima Urbano, (7a ed) São Paulo: Contexto.

Monteiro, A. (2013). Riscos climáticos: hazards, áleas, episódios extremos. Em M.C. Amorim; J. L. Sant'anna Neto (Ed), Climatologia urbana e regional questões teóricas e estudos de caso.

Muniz, F.G.L. (2016). Urbanização e Conforto Térmico: Análise Climática do Centro da Cidade de Sobral - CE. (Dissertação de mestrado). Universidade Estadual do Vale do Acaraú. CE, Brasil.

Muniz, F.G.L. \& Caracristi, I. (2019). A Percepção da população com o clima da cidade de Sobral-CE. Revista Equador, 8(2). $449-467$.

Muniz, F.G.L. \& Caracristi, I. (2019). As Transformações Urbanas e a Sazonalidade: Produtores do Conforto Térmico do Centro da Cidade de Sobral - CE. Revista geografia Ensino \& pesquisa, 22, 1-12.

OKE, T. R. (2006). Initial guidance to obtain representative meteorological observations at urban sites. Instruments and Observing Methods. Vancouver: World Meteorological Organization.

Pereira, A.R; Angelocci, L.R. \& Sentelhas, P.C. (2002). Agrometeorologia: fundamentos e aplicações práticas. Guaíba: Agropecuária.

Sant'Anna Neto, J.L. (1998). Clima e organização do espaço. Boletim de Geografia. Universidade Estadual de Maringá

Sant'Anna Neto, J.L. (2001). História da Climatologia no Brasil: gênese e paradigmas do clima como fenômeno geográfico. (tese de livre docência). Universidade Estadual Paulista, Presidente Prudente, SP, Brasil.

Zavattini, J.A. (2000). O Paradigma da Análise Rítmica e a Climatologia Geográfica Brasileira. Revista Geografia, 25(3), 25-43. 